\title{
Nav2 is necessary for cranial nerve development and blood pressure regulation
}

\author{
Elizabeth M McNeill ${ }^{1}$, Kenneth P Roos ${ }^{2}$, Dieder Moechars ${ }^{3}$, Margaret Clagett-Dame M $^{1,45^{*}}$
}

\begin{abstract}
Background: All-trans retinoic acid (atRA) is required for nervous system development, including the developing hindbrain region. Neuron navigator 2 (Nav2) was first identified as an atRA-responsive gene in human neuroblastoma cells (retinoic acid-induced in neuroblastoma 1, Rainb1), and is required for atRA-mediated neurite outgrowth. In this paper, we explore the importance of Nav2 in nervous system development and function in vivo.

Results: Nav2 hypomorphic homozygous mutants show decreased survival starting at birth. Nav2 mutant embryos show an overall reduction in nerve fiber density, as well as specific defects in cranial nerves IX (glossopharyngeal) and $X$ (vagus). Nav2 hypomorphic mutant adult mice also display a blunted baroreceptor response compared to wild-type controls.
\end{abstract}

Conclusions: Nav2 functions in mammalian nervous system development, and is required for normal cranial nerve development and blood pressure regulation in the adult.

\section{Background}

The vitamin A (retinol) metabolite all-trans retinoic acid (atRA) is essential for normal development of the vertebrate nervous system. During early development, atRA plays a role in patterning the hindbrain and in neuronal specification [1-5]. At later stages of development, atRA is needed for neuronal elongation and axonal pathfinding [6,7]. Vitamin A deficiency has been shown to alter neurite outgrowth from the spinal cord and hindbrain regions in the developing chick, rat and mouse [8-10]. In vitamin A deficient rat embryos, hindbrain patterning is rescued by a level of atRA that is still inadequate to support normal development of the most posterior cranial nerves [9]. In culture, atRA has been shown to increase neurite outgrowth from embryonic sympathetic and dorsal root ganglia neurons and explants [11-15], embryonic spinal cord explants $[12,16]$, and neuroblastoma (NB) cell lines $[17,18]$. However, the mechanism whereby atRA acts to produce these cytoskeletal changes is largely unknown.

The level of atRA in the central and peripheral nervous system of vertebrates [19-21] is regulated through differential expression of both synthetic (Raldh) [22-24]

\footnotetext{
* Correspondence: dame@biochem.wisc.edu

${ }^{1}$ Interdepartmental Graduate Program in Nutritional Sciences, University of
} Wisconsin, Madison, WI, USA and catabolic enzymes (Cyp 26 family) [5,25]. atRA binds to nuclear retinoic acid receptors (Rar $\alpha, \operatorname{Rar} \beta$, and $\operatorname{Rar} \gamma$ ) that together with the retinoid $\mathrm{X}$ receptor regulate the expression of atRA target genes [26]. atRA has been shown to regulate the expression of 3' homeobox genes, which are essential for normal hindbrain patterning. However, genes that lie downstream of atRA and its receptors that are involved in producing changes in neurite outgrowth and axonal elongation remain to be elucidated.

Using a human NB cell line (SH-SY5Y) that extends neurites in response to atRA, our group identified the atRA-responsive gene, retinoic acid-induced in neuroblastoma 1 (Rainb1) [27], which was renamed neuron navigator 2 (Nav2) [28]. Nav2 has also been identified by others as Pomfil2 (pore membrane and/or filament interacting-like protein) [29] and Helad1 (helicase, APCdownregulated) [30]. Nav2 is rapidly induced (within 4 hours) by atRA and has been detected in the developing rat nervous system, where its expression is sensitive to both high and low levels of atRA [27]. Loss-of-function studies show that Nav2 induction is required for atRA to induce neurite outgrowth in human NB cells [31].

Nav2 is a member of the neuron navigator family comprising Nav1, 2 and 3 [28]. The Nav2 gene is composed of 38 exons, and the largest open reading frame 
encodes a protein of $261 \mathrm{kDa}$. Several alternatively spliced variants have been identified, and a shorter protein based on an alternative start site upstream of exon 13 has been proposed based on PCR studies [32]. Of the three Nav family members, Nav2 shows most similarity to the Caenorhabditis elegans homolog unc-53, which is essential in the longitudinal migration of several cell types, including neurons, developing sex myoblasts, and the excretory cell [33-36]. In the nervous system, unc-53 is required for normal mechanosensory neuron elongation [36,37]. Transgene expression of human full-length Nav2 rescues the defects in unc-53 mutant mechanosensory elongation [6,31]. Thus, studies both in C. elegans as well as in cultured human NB cells support a role for Nav2 in neurite outgrowth and axonal elongation.

The acuity of several sensory systems (olfactory, auditory, visual) and the ability to sense pain is impaired in the adult hypomorphic Nav2/unc-53H2 mutant mouse [32]. The $u n c-53 H 2$ mutant was generated using a gene trap method in which insertion of a neo cassette occurred between exons 7 and 8 of the unc-53H2 (Nav2) gene, abolishing expression of the full-length Nav2 transcript and protein, but leaving expression of the shorter transcript undisturbed. The long transcript is required for atRA to induce neurite outgrowth in human NB cells [31] and is expressed most abundantly in the nervous system [27]. In the present work, we examine development of the embryonic nervous system in the Nav2/unc$53 \mathrm{H} 2$ mutant, with particular emphasis on the hindbrain region, known to be particularly sensitive to the adverse effects of vitamin A deficiency. In addition, the function of hindbrain nerves in the maintenance of blood pressure in the adult Nav2/unc-53H2 mutant is examined.

\section{Results}

\section{Postnatal survival is reduced in Nav2 hypomorphic} mutant mice

When examined at embryonic day (E) 10.5 or E17.5, no significant reduction in the expected number of homozygous mutant offspring was observed; however, increased lethality was observed after postnatal day (P)0 (Figure 1). At P0, the number of homozygous Nav2 hypomorphic mice was $10 \%$ lower than expected, and by P28, this number had risen to $36 \%$. The reason for early neonatal death was sought by examining $\mathrm{Nav}^{-/-}$mice that died shortly after birth (P0). By external examination, there was never any evidence of a milk spot in the stomach, indicating that the neonates failed to suckle. In addition, when the $\mathrm{Nav}^{-1-}$ neonates $(\mathrm{n}=3)$ were fixed and subjected to serial sectioning followed by hematoxylin and eosin staining, none of the mice showed evidence that the lungs had ever inflated (data not shown). This is consistent with the finding of a persistent opening of the foramen ovale, an opening between the right and left

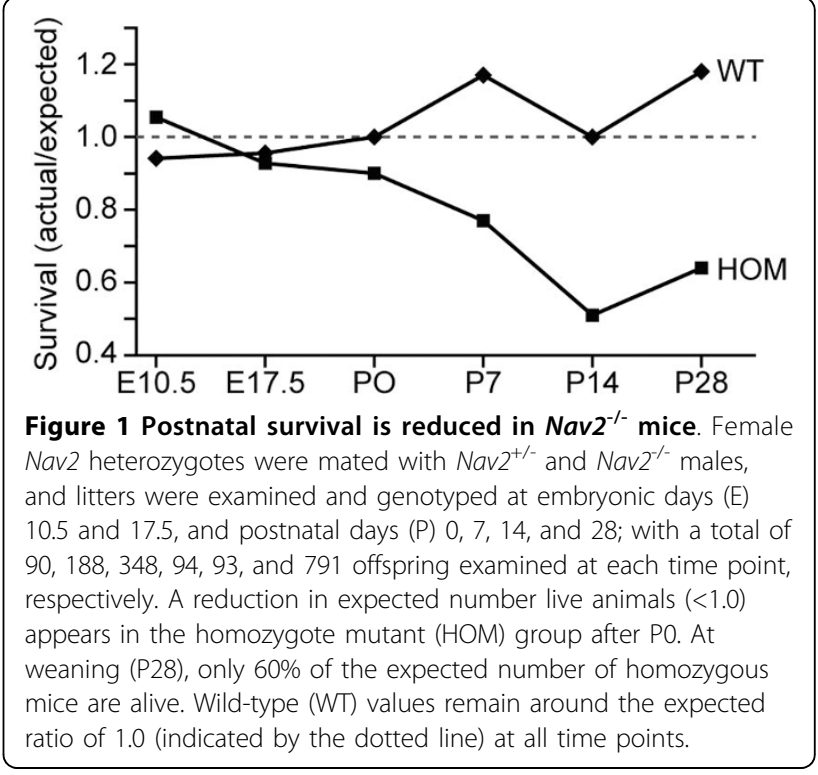

atrium that normally closes at birth after the lungs fill with air and the pulmonary capillary bed opens (data not shown). The cause of neonatal death at later times was not determined, although it did not appear to be related to an inability to suckle, as the weight of $\mathrm{Nav}^{-/-}$neonates at P7 and P14 did not differ from that of the wild-type controls (data not shown).

\section{Overall nerve density is reduced in the Nav2 hypomorphic mutant}

In order to determine whether the atRA-responsive gene Nav2 influences early nervous system development, hypomorphic $\mathrm{Nav}^{-/-}$mutant embryos were stained with an antibody to neurofilament protein $(2 \mathrm{H} 3)$ and compared to wild-type controls at E11.5. The expression of a reporter gene driven by $\mathrm{Brn} 3 a$ in the developing sensory nerves was also examined at E12.5, E13.5, and E15.5 of development. An overall decrease in neurofilament staining was particularly notable in the cranial nerves as well as the mesencephalic tract and the dorsal root ganglion (DRG) neurons in $\mathrm{Nav}^{-1-}$ hypomorphic mutant mice relative to their wild-type littermates (Figure 2). To quantify the overall decrease in nerve fiber density in these regions, wildtype and homozygous embryos from $\mathrm{Nav}^{+/-} \times \mathrm{Nav}^{+/-}$ crosses were scored blinded for relative density of neurofilament staining across litters from the same staining runs. Nearly $40 \%$ of the $\mathrm{Nav}^{2 /-}$ embryos were classified as exhibiting decreased nerve fiber density, while only $7 \%$ of the wild-type animals scored positive for this effect (Table 1). The percentage of affected heterozygote embryos was intermediary between that of the homozygotes and wildtype controls (data not shown). The number of homozygous mutants showing a reduction in nerve fiber density 

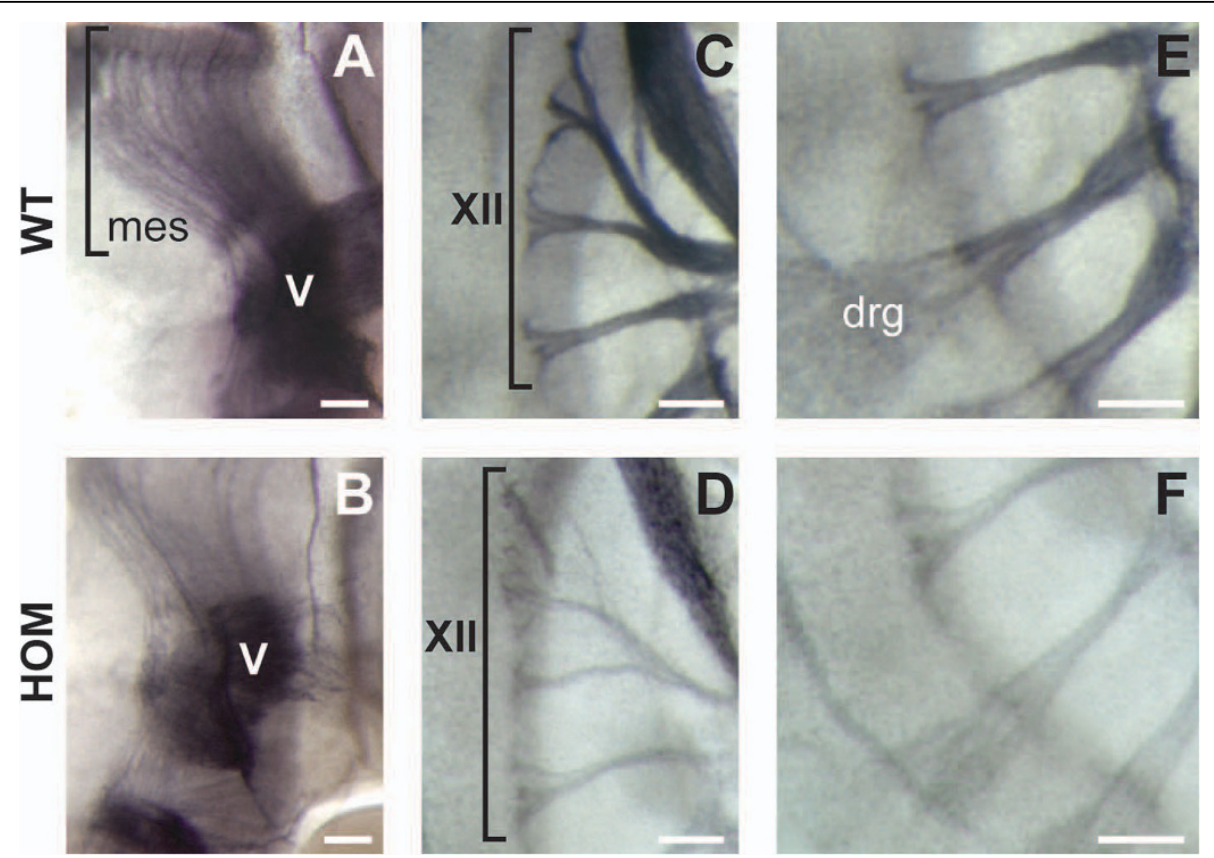

Figure 2 Nerves are less densely stained by an antibody to neurofilament in Nav2 homozygous mutant embryos at E11.5. The (A) mesencephalic tract (mes) nerve fibers, (C) cranial nerve XII, and (E) dorsal root ganglia (drg) nerves are shown in wild-type (WT) mice. (B, D, F) $\mathrm{Nav2}^{-1-}$ littermates show decreased staining of nerve fibers in these same regions. The images shown here are representative of the majority of those scored in Table 1 as positive for a reduction of nerve fiber density. Scale bar: $100 \mu \mathrm{m}$.

was found to be statistically different from their wild-type counterparts (Table 1).

The development of the sensory neurons was further examined by crossing a Brn3a-lac $Z$ reporter mouse strain [38] into the Nav2 mutant background. Brn3a is a POU-domain transcription factor expressed in primary sensory neurons of the cranial and dorsal root ganglia and in specific neurons in the caudal central nervous system. Brn3a-lacZ heterozygotes appear to show normal sensory neuron development [39]. Using this reporter, an overall reduction in sensory nerve fiber staining was observed in the mesencephalic tract, at E12.5 and E13.5 (Figure 3 and data not shown), and in the spinal

Table 1 Percentage of animals with decreased nerve fiber density

\begin{tabular}{lc}
\hline Genotype & Decreased nerve fiber density \\
\hline Wild type & $7 \%(2 / 27)$ \\
Homozygote & $39 \%(37 / 95)$ \\
\hline
\end{tabular}

Values shown in parentheses are the number of affected embryos over the total number of embryos evaluated; Z-score $=-3.1 ; P$-value $\leq 0.01$. The determination of a decrease in nerve fiber density was made when an embryo showed an overall reduction in neurofilament staining in the region of the cranial nerves (V to XII) compared to wild type littermates. In addition, a subset of embryos (23 wild-type and $63 \mathrm{Nav2}^{-1 /}$ ) was also scored for reduction in staining in the mesencephalic tract and dorsal root ganglion neurons. A similar percentage of homozygote embryos showed a reduction of nerve fiber density in both regions (30\%), whereas only $4 \%$ of the wild-type group was affected. nerves at E15.5 in the homozygote mutants compared to wild-type and heterozygous controls (Figure 3).

\section{Nav2 hypomorphic mutants have defects in cranial nerves IX and $\mathrm{X}$}

The development of the cranial nerves (CNs) was examined by staining embryos at E11.5 in whole-mount with an antibody to neurofilament protein. While the gross organization of CN V (trigeminal), VII/VIII (vestibuloacoustical), XI and XII in the Nav2 $2^{-1-}$ mutants did not appear different from the wild-type controls, this study revealed the development of CN IX (glossopharyngeal) alone, or together with $\mathrm{CN} \mathrm{X}$ (vagus), was altered in a significant number of $\mathrm{Nav2}^{-1-}$ hypomorphic embryos. Normally at this stage of development, the distal ganglia of CN IX is connected to the proximal ganglia and the neural tube by tightly fasiculated axons, originating both from the neurons of the distal ganglia (placode-derived) as well as from axons projecting from the proximal ganglion neurons (neural crest-derived) and the motor neurons originating at the level of rhombomere (r)6/7 of the neural tube (Figure 4A). The most frequently observed phenotype in the $\mathrm{Nav}^{-/-}$hypomorphic embryos was either the complete loss of nerve fibers connecting the distal ganglia of CN IX to the hindbrain or else a severe reduction in the density of this nerve branch (phenotype 1; 39\% or 52 out of 133 embryos; 


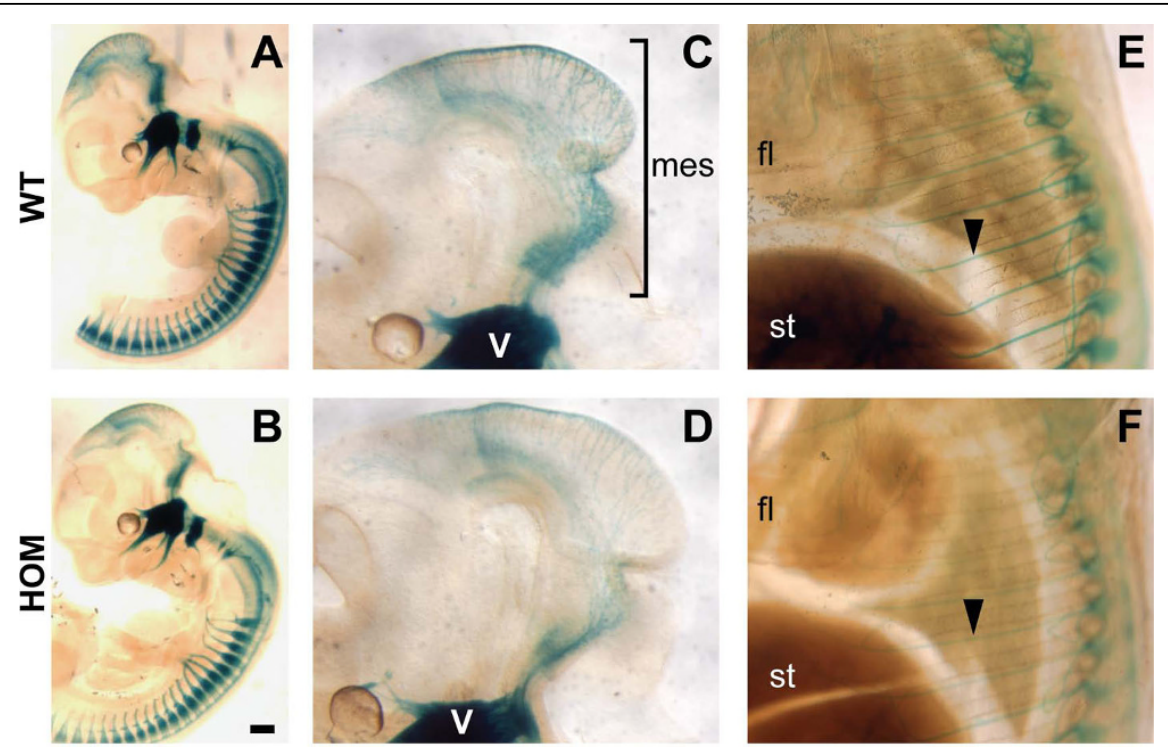

Figure $3 \mathrm{Nav2}^{-/-} / \mathrm{Brn}_{3} \mathrm{a}-\mathrm{lacZ} \mathrm{Z}^{+/-}$mice show a reduction in lacZ staining of sensory nerves compared to their $\mathrm{Nav2}^{+/+} / \mathrm{Brn}^{3 a-l a c Z^{+/-}}$ littermates. (A) Nav2 wild-type (WT) and (B) homozygote mutant (HOM) littermates in a Brn3a-lacZ ${ }^{+/-}$background shown at the same developmental stage (E13.5). (C, D) Specifically, there appear to be fewer sensory neurons in the mesencephalic tract (mes) region in the Nav2 ${ }^{-1} /$ Brn3a-lac $Z^{+/-}$embryo (D) (E13.5) compared to the wild-type (WT) littermate (C) (E13.5). (E, F) A reduction in spinal nerve staining is also observed in the Nav2 ${ }^{-1} / \mathrm{Brn}_{3}$ a-lacZ $\mathrm{Z}^{+-}$embryo at E15.5 (compare (F) to the wild-type in (E)). The results shown are representative of nine wild-type and nine

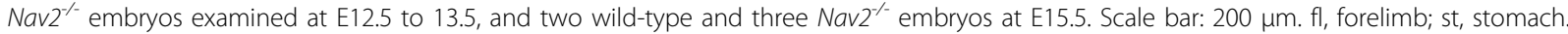

Figure 4B). In the second phenotype, the IXth and Xth nerves were fused (Figure 4C), whereas these nerves are normally well separated at this stage (Figure 4A). Phenotype 2 was observed in 38 out of 133 or $29 \%$ of homozygous Nav2 hypomorphic embryos. Overall, the penetrance of phenotypes 1 and 2 together was $60 \%$, with nearly half of the $\mathrm{Nav2}^{-/-}$embryos affected on both sides. There was a statistically significant difference in incidence of CN IX/X defects in the $\mathrm{Nav} 2^{-/-}$hypomorphs compared to the wild-type group for each phenotype (1 and 2), as well as in combination (Table 2).

The cranial nerve abnormalities observed here could arise from perturbation of several different developmental events, including abnormalities of early hindbrain patterning, neural crest cell migration, neuronal survival and/or elongation. Nav2 mRNA expression was found

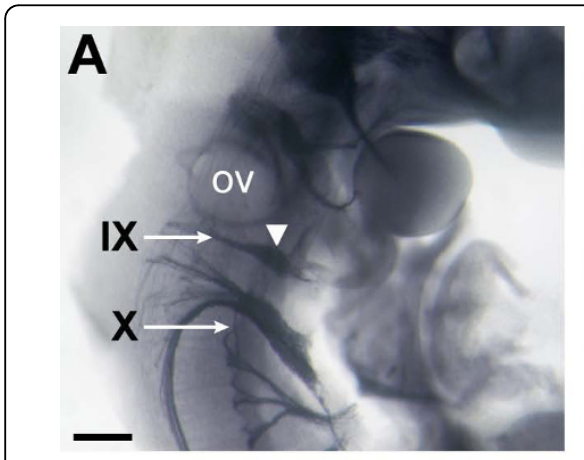

Normal

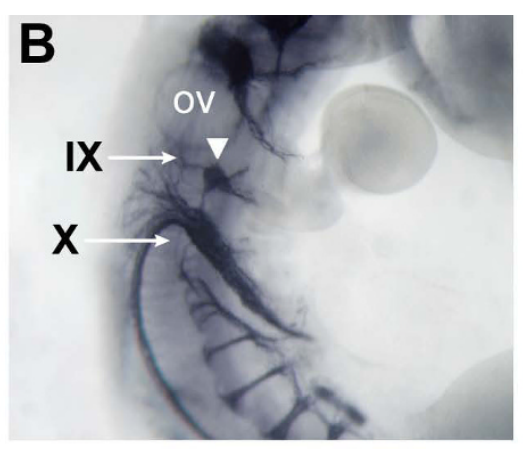

Phenotype 1:

Weak/No Connection

IX to Hindbrain

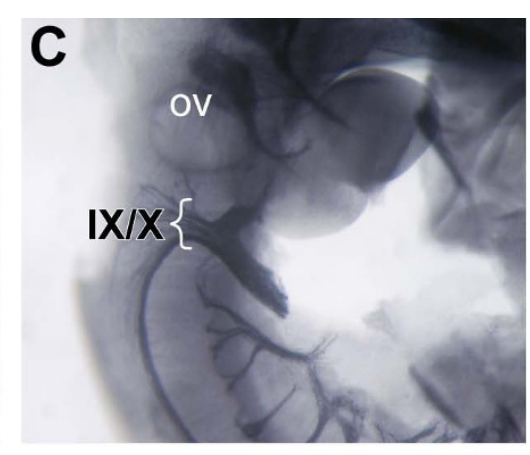

Phenotype 2: Fusion IX/X

Figure 4 Cranial nerve IX and $\mathbf{X}$ defects are found in homozygous Nav2 hypomorphic mutants. Whole-mount immunostaining for neurofilament protein in (A) a normal Nav2 ${ }^{+/+}$embryo, and in (B, C) Nav2 ${ }^{-/}$embryos at E11.5. In the Nav2 ${ }^{-/-}$embryo with phenotype 1 (B), the nerve fibers connecting the distal ganglia of IX (white arrowhead) to the proximal ganglia and hindbrain exit point are missing. In the Nav2 mutant showing phenotype 2 (C), the IXth and Xth nerves are fused (brackets). Cranial nerves are indicated in roman numerals: IX, glossopharyngeal; X, vagus; ov, otic vesicle. Scale bar: $200 \mu \mathrm{m}$. 
Table 2 Percentage of embryos (sides) examined with cranial nerve abnormalities

\begin{tabular}{lccc}
\hline Genotype & Phenotype 1: gIX weakly or not connected to hindbrain & Phenotype 2: CN IX/X fusion & Phenotypes $\mathbf{1}$ and $\mathbf{2}$ combined \\
\hline Wild type & $7 \%(4 / 59)$ & $7 \%(4 / 59)$ & $14 \%(8 / 59)$ \\
Homozygote & $27 \%(72 / 266)$ & $17 \%(45 / 266)$ & $44 \%(117 / 266)$ \\
\hline
\end{tabular}

Values shown in parentheses are the number of abnormal observations over the total number of observations (60 wild-type and 133 homozygous embryos were scored on both the right and left side; one wild-type side (observation) was lost). Phenotype 1: Z-score $=-3.33$ and $P$-value $\leq 0.001$. Phenotype 2 : Z-score $=-1.97$ and $P$-value $\leq 0.05$. Phenotypes 1 and 2 combined: $Z$-score $=-4.35 ; P$-value $\leq 0.0001$. gIX, ganglia IX.

very early in the normal mouse embryo at the late-bud to early headfold stage and was similar to the distribution pattern described previously in the rat embryo (data not shown) [27]. At E10.5, robust expression of the Nav2 transcript was observed in the mesencephalic tract region (Figure 5A) as well as the ganglia of the trigeminal (V, Figure 5B), facial and vestibulocochlear (VII/VIII, Figure 5C), glossopharyngeal (IX, Figure 5D1) and vagus (X, Figure 5E1) nerves. Expression was also seen in the developing neural tube (Figure 5B-F) and the dorsal root ganglia (Figure 5F). At E10.5, a time point when neurites are extending from the ganglia,
Nav2 expression co-localized with differentiating neurons identified by $\beta$-III tubulin staining in both the glossopharyngeal and the vagus ganglia (Figure 5D2 and $5 \mathrm{E} 2$, respectively). At earlier stages, Nav2 was found most abundantly in the neural tube and mesencephalon but was not detected in the region of the placodes or migrating neural crest (data not shown). Thus, the expression pattern of Nav2 was most consistent with either a role in hindbrain patterning and/or neuronal maintenance or elongation.

The hindbrain develops seven to eight transient lineage-restricted compartments called rhombomeres, and

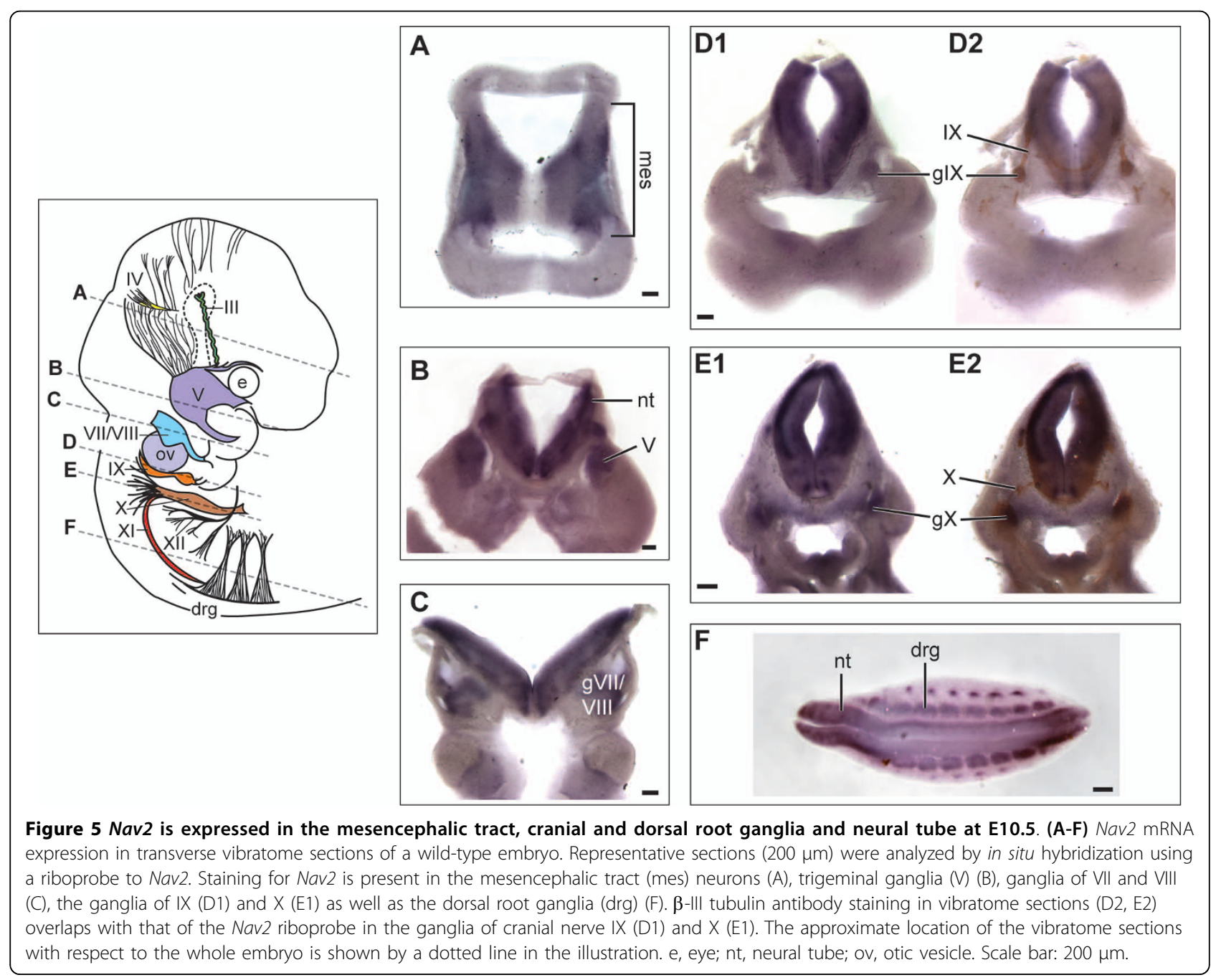


this segmented structure is closely involved in the development of the cranial nerves [40]. In order to determine whether an alteration in early hindbrain development might contribute to the $\mathrm{CN}$ defects observed in $\mathrm{Nav} 2^{-/-}$ hypomorphic embryos, the expression of KROX20 (EGR2) protein, and Hoxa3, Hoxb3, and Hoxb4 mRNAs were studied. These transcription factors all play important roles in hindbrain patterning and also serve as markers of the presumptive rhombomere borders at early times in development. EGR2 is expressed in r3 and r5, and is required for the development of both of these segments [41]. Hoxa3 and Hoxb3 are expressed in the neuroepithelium caudal to the $\mathrm{r} 4 / 5$ border, and the disruption of Hoxa3 has been shown to cause defects in CN IX and X that are highly similar to those described here for the $N a v 2^{-/-}$embryos [42]. Hoxb4 is expressed caudal to r6/7, serving as a useful marker for caudal hindbrain development [40]. When the expression of EGR2 was examined in embryos at $8 \mathrm{~s}$, similar immunostaining in $\mathrm{r} 3$ and $\mathrm{r} 5$ was observed both in $\mathrm{Nav}^{+/+}$and $N a v 2^{-1-}$ embryos (Figure 6A, B). No difference in the staining pattern of Hoxa3, Hoxb3, and Hoxb4 was detected between wild type and homozygote mutants (Figure 6C-F and data not shown). These results indicate that hindbrain rhombomeric specification was not altered in homozygous $\mathrm{Nav} 2^{-/-}$hypomorphic mutant embryos. Neural crest cell migration from the hindbrain was examined by in situ hybridization using a probe to Crabp1, which is expressed in neural crest cells contributing to the IXth and Xth cranial nerves [43]. Crapb1 expression appeared similar in both homozygote mutants and wild-type embryos at E9.5 (Figure 6G-I), suggesting that neural crest cell migration defects may not account for the cranial nerve defects observed in the homozygous Nav2 mutant mice. These findings along with the expression pattern of Nav2 suggest that Nav2 may be exerting its effects on some aspect of neuronal elongation or survival rather than patterning or neural crest cell migration.

\section{The baroreceptor response is blunted in $\mathrm{Nav2}^{-1-}$ hypomorphic mutants}

Because both CN IX and X are involved in the regulation of cardiac function, and because these nerves were affected in the mutants, the baroreceptor reflex was compared in $\mathrm{Nav2}^{-/-}$and $\mathrm{Nav2^{+/+ }}$ adult mice. The baroreceptor reflex is a mechanism to decrease heart rate when blood pressure rises and this reflex is dependent upon the function of both CN IX and X. Baroreceptors are stretch-sensitive mechanoreceptors; they are present in the carotid sinus, where they are innervated by CN IX, and in the aortic arch, where innervation by $\mathrm{CN} \mathrm{X}$ takes place. When blood pressure rises, carotid and aortic distension occurs, leading to baroreceptor activation and signaling of the afferent fibers of CN IX and $\mathrm{X}$ to the brainstem. This leads to inhibition of the sympathetic branch of the autonomic nervous system as well as an increase in vagal ( $\mathrm{CN} \mathrm{X)}$ efferent signaling via muscarinic receptor activation to the heart. Thus, the heart rate is reduced to lower the blood pressure back to the baseline level. A decline in blood pressure operates in the opposite compensatory manner to increase heart rate to restore normal blood pressure. Figure 7 shows a schematic of the afferent and efferent nerve connections involved in the baroreceptor reflex.

In order to test $\mathrm{Nav}^{-/-}$mice for this baroreceptor response, blood pressure changes were induced by pharmacological means using the vasoconstrictor angiotensin II (alpha 1 adrenergic agonist) and the vasodilator nitroprusside. The ability of $\mathrm{Nav} 2^{-/-}$mice to compensate for the drug-induced increase or decrease in blood pressure by decreasing and increasing heart rate, respectively, was compared to their wild-type counterparts. Initially, baseline data were recorded for at least 15 to 30 minutes, and these results showed there was no difference in systolic blood pressure or heart rate between the Nav2 hypomorphic mutants and wild-type mice prior to any drug intervention (Table 3). Mice were then treated with angiotensin II to induce an increase in blood pressure. In the Nav2 mutants, the expected decrease in heart rate in response to the change in blood pressure was significantly less than that observed in the wild-type mice at both the $10 \mu \mathrm{g} / \mathrm{kg}$ and $20 \mu \mathrm{g} / \mathrm{kg}$ doses of angiotension II (Figure 8A). Approximately 56\% (5 out of 9) $N a v 2^{-1-}$ mutant mice showed a change in heart rate relative to the change in blood pressure (Delta value) below that of the lowest responder in the wild-type group in response to the $10 \mu \mathrm{g} / \mathrm{kg}$ dose of angiotensin II (data not shown). Thus, Nav2 $2^{-/-}$mice showed less ability to produce a compensatory reduction in heart rate in response to the vasoconstrictor effects of angiotensin II.

Next, the vasodilator sodium nitroprusside was used to examine the responsiveness of $\mathrm{Nav} 2^{-/-}$hypomorphic mutant mice to a drop in blood pressure. Normally, a nitroprusside-induced drop in blood pressure should produce an increase in heart rate. However, a blunted heart rate response was observed in the hypomorphic $N a v 2^{-1-}$ mutants (Figure 8B). At the $10 \mu \mathrm{g} / \mathrm{kg}$ dose of nitroprusside, the hypomorphic mutant mice, on average, showed a heart rate increase only one-third that of the wild-type mice. At both the 20 and $40 \mu \mathrm{g} / \mathrm{kg}$ doses, wild-type mice became less responsive, and showed a change similar in magnitude to that of the Nav2 mutants. This is consistent with work showing the heart rate/blood pressure ratio normally declines with increasing doses of nitroprusside [44].

In addition to a reduced ability to increase or decrease heart rate appropriately in response to nitroprusside and 

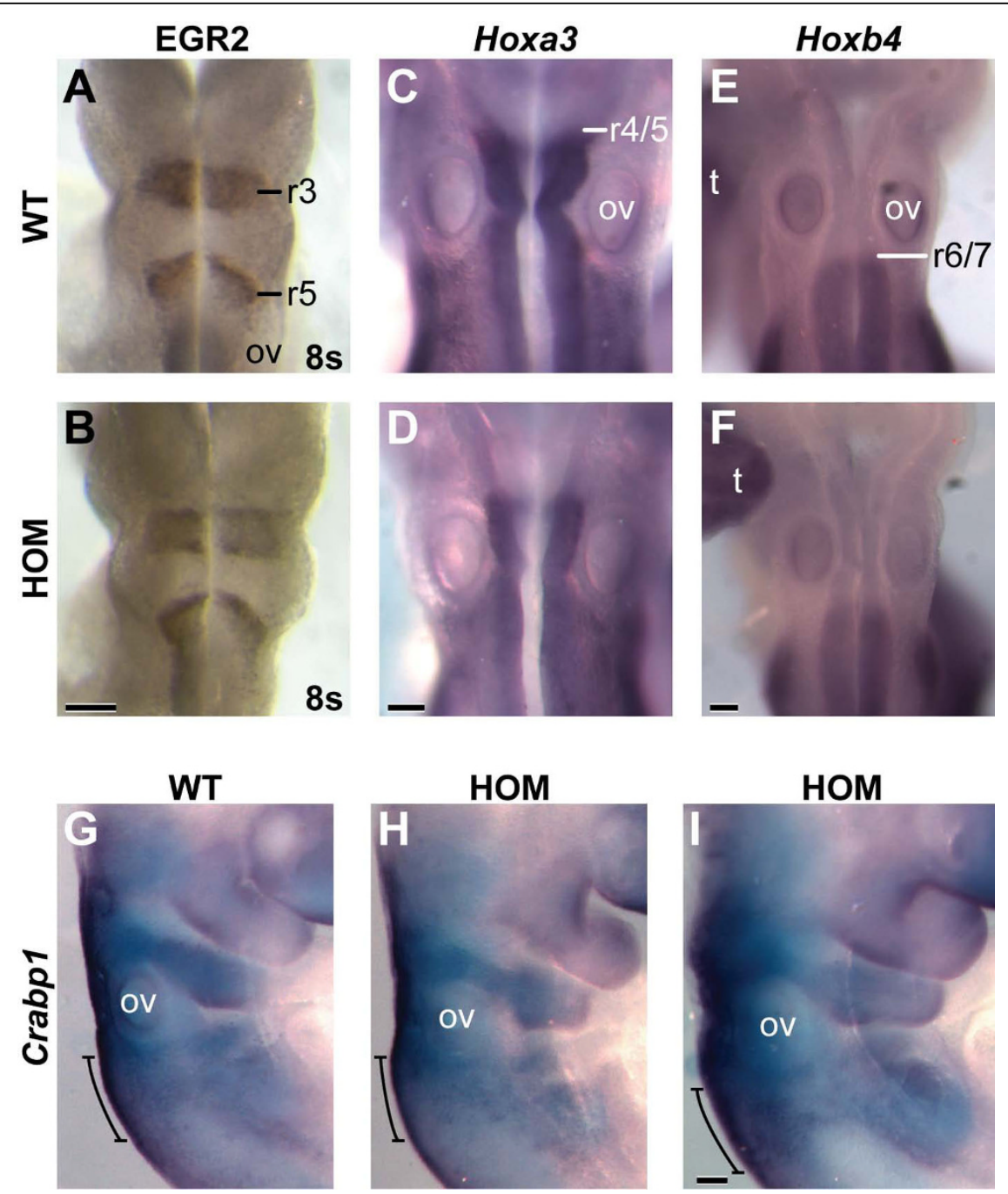

Figure 6 Expression of EGR2 (KROX20), Hoxa3, Hoxb4, and Crabp1 is unaltered in the hindbrain of Nav2 homozygous mutant embryos. Whole-mount immunohistochemistry for EGR2 shows staining in presumptive rhombomeres $r 3$ and $r 5$ at $8 s$ in both (A) wild-type (WT) and (B) Nav2 ${ }^{--}$(HOM) embryos. (C,D) In situ hybridization analysis of Hoxa3 mRNA at E9.5 shows staining in the neuroepithelium caudal to the $r 4 / 5$ border in both genotypes. Hoxb4 mRNA at E9.5 is expressed caudal to the r6/7 border in both (E) wild-type and (F) Nav2 ${ }^{-1-}$ embryos. (G-I) Crabp1 mRNA at E9.5 is expressed in the neural crest cells, including those contributing to the IXth and X cranial nerves (bracket) in both wild-type (G) and $\operatorname{Nav2}^{-1-}(\mathrm{H}-\mathrm{l})$ embryos. A total of ten 8s wild-type and Nav2 ${ }^{-1-}$ embryos each were studied for EGR2 staining; 8 and 19, and 7 and 12 wild-type and $\mathrm{Nav2}^{-1-}$ embryos were examined for Hoxa3 and Hoxb4, respectively. Seven wild-type and $13 \mathrm{Nav}^{-/-}$embryos were studied for Crabp1 staining. ov, otic vesicle; t, tail. Scale bar: $200 \mu \mathrm{m}$.

angiotensin II, respectively, the Nav2 hypomorphic mutant mice showed a much longer duration of pressure change after both angiotensin and nitroprusside treatment that was most likely due to the blunted heart rate response (data not shown).

To determine whether the heart in $\mathrm{Nav2}^{-/-}$mutants was able to respond appropriately to parasympathetic and sympathetic inputs, propranolol, a non-selective beta adrenergic receptor blocker $(1 \mathrm{mg} / \mathrm{kg})$ was used to block sympathetic contributions, and glycopyrrolate, a muscarinic receptor antagonist $(100 \mu \mathrm{g} / \mathrm{kg})$, was used to block parasympathetic input. Following propanolol administration, both wild-type and $\mathrm{Nav}^{-/-}$mice showed a reduction in heart rate consistent with blocking sympathetic input, and following glycopyrrolate, both groups showed an increase in heart rate consistent with blocking parasympathetic input. Thus, the responsiveness of $\mathrm{Nav}^{-1-}$ mice to sympathetic and parasympathetic input from the medulla was intact. Furthermore, the magnitude of the blocker-induced changes in heart rate did not differ between the genotypes (Table 4). After application of the blockers, a $40 \mu \mathrm{g} / \mathrm{kg}$ dose of each of the 


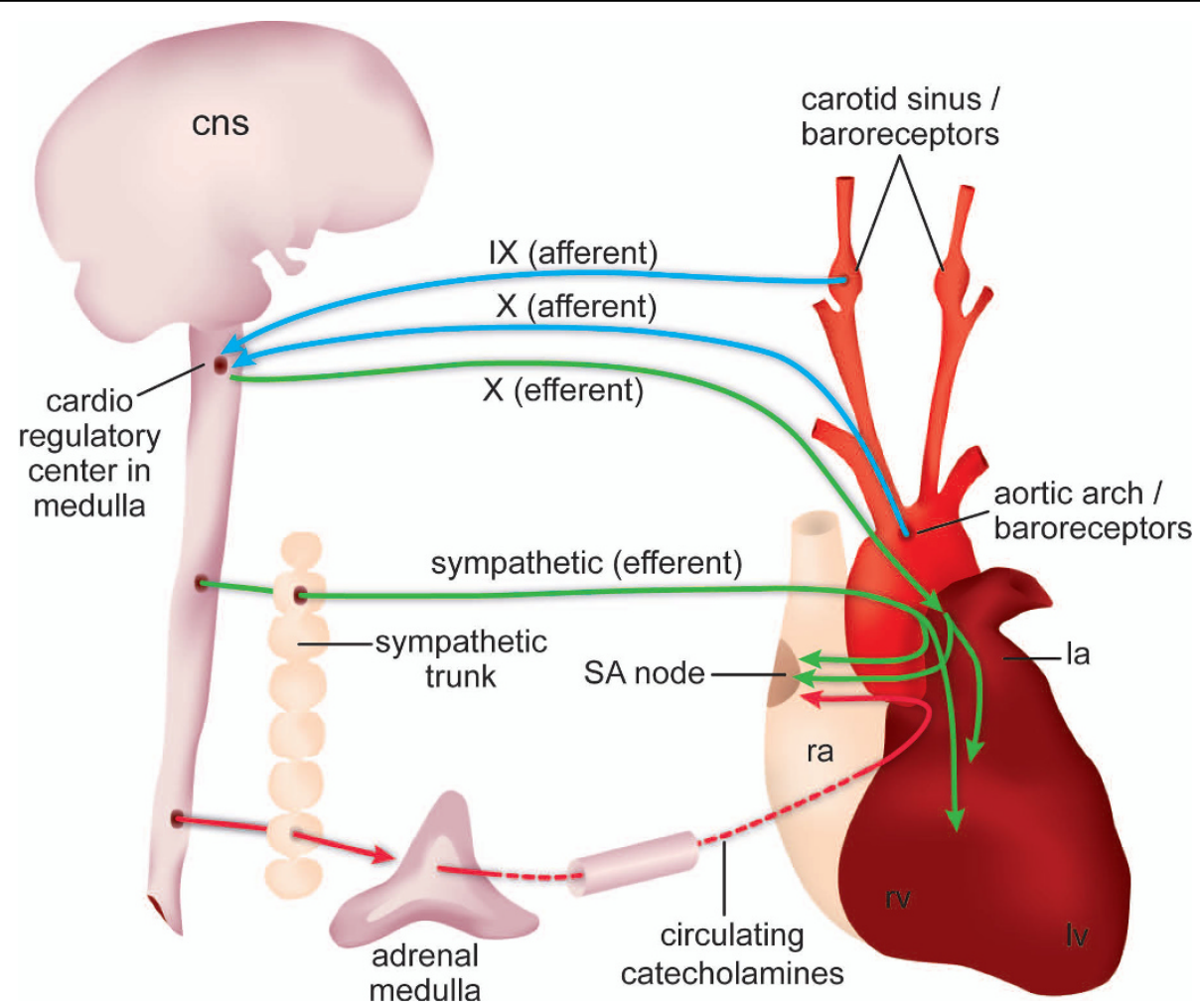

Figure 7 Diagram of sympathetic and parasympathetic regulation of the baroreceptor reflex. Schematic shows the nerves involved and areas innervated in the baroreceptor reflex arc. Adapted from [63]. CNS, central nervous system; la, left atrium; Iv, left ventricle; ra, right atrium; $r v$, right ventricle; SA, sinuatrial.

Table 3 Baseline heart rate and blood pressure in Nav2 hypomorphic mutant and wild-type mice

\begin{tabular}{lcc}
\hline Genotype & Heart rate (beats/minute) & Systolic BP $\mathbf{( m m H g})$ \\
\hline Wild type & $476 \pm 21.3$ & $92.9 \pm 3.3$ \\
Homozygote & $523 \pm 21.5$ & $90.4 \pm 3.7$ \\
\hline
\end{tabular}

The baseline heart rate and systolic blood pressure (BP) are not significantly different when examining the pooled averages using a two-tailed $t$-test. Values are mean \pm standard error of the mean.

drugs, angiotensin II or nitroprusside, was administered. There was a complete block of the baroreceptor response under both blocks with both treatment conditions, showing that adrenergic and muscarinic receptor response was blocked. Taken together, this work indicates that a defect in receptor signaling was not responsible for the diminished response in the $N a v 2^{-/-}$mice. Overall, these baroreceptor studies showed that the hypomorphic $\mathrm{Nav} 2^{-/-}$mutant mice exhibited a blunted response to changes in blood pressure consistent with abnormal functioning of CN IX and X.

\section{Discussion}

In the present study, nervous system development was studied in the unc-53H2 (Nav2) hypomorphic mutant mouse [32]. The results show that Nav2 is important for the normal development of neuronal fibers during embryonic development, and that the full-length protein plays a role in the development of CN IX (glossopharyngeal) and $\mathrm{CN} X$ (vagus). Postnatal survival is reduced in Nav2 hypomorphic mutant mice, and those that do survive to adulthood show a blunted ability to compensate for changes in blood pressure, a response requiring signaling through CN IX and X.

The observation that Nav2 hypomorphic mutant embryos show a reduction in overall nerve fiber density is consistent with the proposed role for this gene in neurite outgrowth [31]. In addition, it may help to explain how elimination of the full-length NAV2 protein contributes to the behavioral phenotypes reported previously in the unc-53H2 hypomorphic mutant mouse, including impaired acuity of several sensory systems. In adult mice, Peeters et al. [32] reported there was hypoplasia of the optic nerve; however, the morphology of the developing embryonic nervous system was not examined. In the present study, analysis of neurofilament antibody staining in $\mathrm{Nav}^{-/-}$(unc-53H2) embryos at E11.5, as well as analysis of nerve development at E13.5 in Nav2 $2^{-/-} /$Brn3a-lac $Z^{+/-}$embryos, indicates that overall neuronal density, including that of the sensory neurons, is diminished. This was particularly evident in 


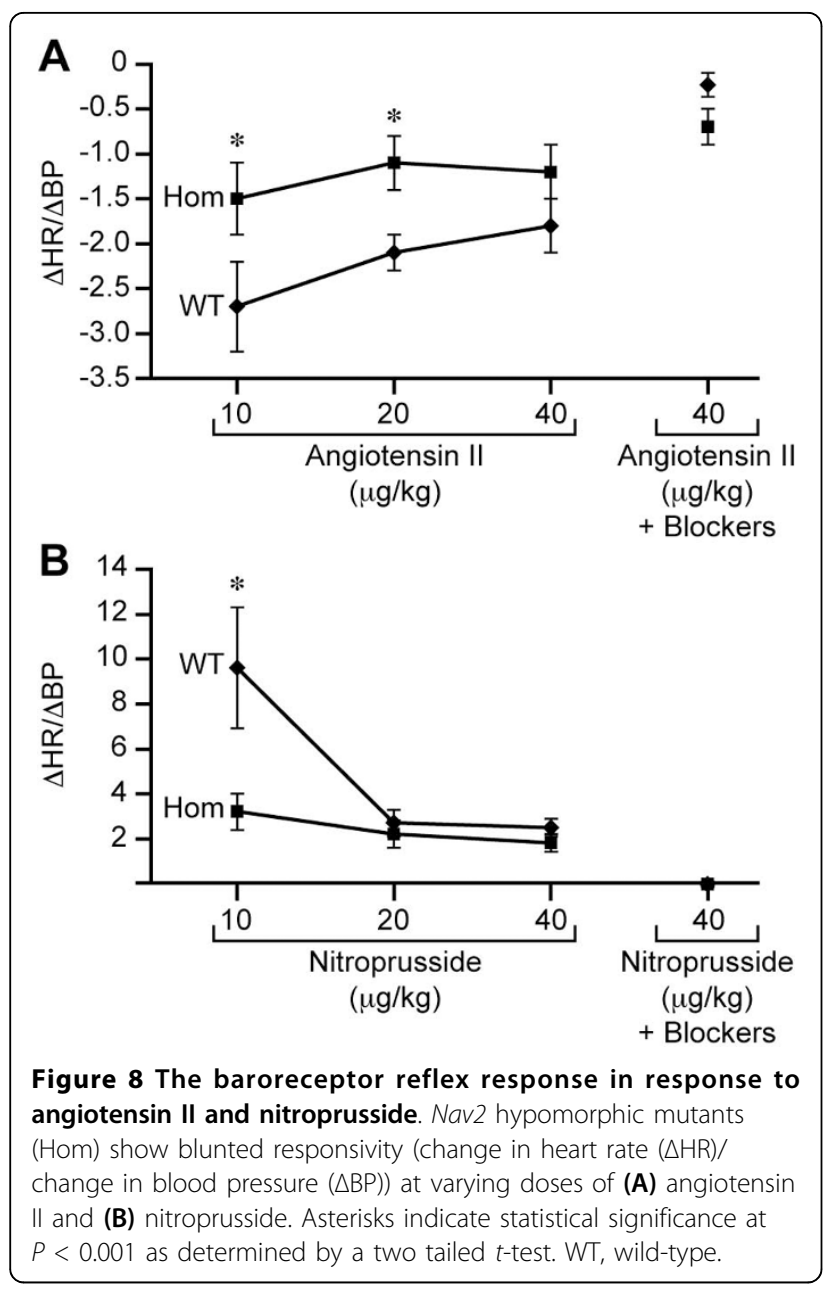

the trigeminal mesencephalic tract neurons and in the dorsal root ganglia. The dorsal root ganglia contain cell bodies of sensory neurons that are located along the spinal nerves and their processes are involved in sensing touch, stretch, temperature and pain. A reduction in the density of sensory neuron fibers in the $\mathrm{Nav}^{-/-}$mutants is consistent with previous work showing that these mice have impaired sensory function [32].

Consistent with the present observation of a reduction in nerve fiber density in Nav2 hypomorphic mutants, is strong evidence, both from work in cell culture and in C. elegans, supporting a role for Nav2 in neurite outgrowth and axonal elongation. In human NB cells, knock-down of full-length Nav2 eliminates atRAinduced neurite outgrowth, and ectopic expression of human Nav2 in the mechanosensory neuron rescues the ability of the unc-53 mutant to extend axons [31]. Nav2 has been proposed to function in neurite outgrowth by altering the structure of the cytoskeleton. The $261 \mathrm{kDa}$ NAV2 protein contains several functional domains, including a calponin-homology domain at its amino terminus, several coiled-coil regions, a SH3-binding motif, a putative cytoskeletal-interacting domain, and a carboxy-terminal AAA-domain. In human NB cells, NAV2 is found closely associated with cytoskeletal elements, including microtubules and neurofilament proteins, and the cytoskeletal-interacting domain is required for NAV2 to interact with microtubules [31]. It has also been proposed that the neuron navigator family is involved in reorganizing the cytoskeleton to guide cell shape changes by serving as microtubule plus-end tracking proteins $[45,46]$. Based on work in C. elegans, UNC53 has been proposed to act as a scaffold that links ABL-1 to the ARP2/3 complex to regulate actin cytoskeleton remodeling [47]. Thus, although the molecular details concerning how Nav2 functions in neuronal elongation remain to be elucidated, the present study shows that Nav2 is essential for maintaining the density of neuronal fibers in the mouse, and that this function is exerted early in the developing nervous system of embryos.

In addition to nerve fiber density changes, the development of CN IX (glossopharyngeal) and CN X (vagus) are particularly affected in the Nav2 hypomorphic mutants. Nearly $60 \%$ of these mutants show a reduction in or lack of axonal connection between the distal ganglia of CN IX with the proximal ganglion and hindbrain, and/or a fusion of the distal ganglia of CN IX and X. The cranial nerves develop in register with lineagerestricted compartments called rhombomeres. Hindbrain development is a highly conserved and tightly regulated process in vertebrate animals and plays an important role in directing the pathways of neural crest migration ultimately producing cranial nerves and craniofacial structures that are integral to hindbrain function [48]. The disruption of a number of genes involved in the establishment and maintenance of rhombomeres are known to affect cranial nerve development [40]. However, analysis of selected markers of hindbrain

Table 4 Heart rate changes after sequential administration of a muscarinic receptor and a beta-adrenergic receptor blocker

\begin{tabular}{lcccc}
\hline & Baseline & Glycopyrrolate & $\boldsymbol{\Delta}$ & Propranolol \\
\hline Wild type & $489 \pm 22$ & $526 \pm 15$ & $37 \pm 16$ & $448 \pm 10$ \\
Homozygote & $522 \pm 17$ & $563 \pm 17$ & $41 \pm 13$ & $453 \pm 19$ \\
\hline
\end{tabular}

There is no significant difference between homozygous mutant and wild-type heart rate changes with either glycopyrrolate or propranolol. Values are mean \pm standard error of the mean. 
segmentation did not reveal abnormalities in rhombomere identity in Nav2 mutants; thus, the defects in CN IX and $\mathrm{X}$ are not likely the result of defects intrinsic to the hindbrain neuroepithelium.

CN IX and X defects similar to those observed here in Nav2 hypomorphic mice have been reported in other genetic mutants, including Hoxa3, CoupTF1, and Sall3 $[42,43,49,50]$. In a number of mutants showing fusion of CN IX and X, specification and segmentation of rhombomeres is reportedly normal, whereas perturbation of later developmental events involving precursor cell migration and/or axon extension have been proposed as a causative factor [49-51]. The cells that contribute to $\mathrm{CN}$ IX and $\mathrm{X}$ arise from the hindbrain (motor components), neural crest cells (NCCs) and the epibranchial placodes. NCCs arise from the dorsal edge of the neural tube and form both the proximal ganglion sensory neurons of CN IX and X, as well as the glial cells within the proximal and distal ganglia. The distal ganglion sensory neurons of CN IX and X are derived from epibranchial placodes. In addition to sensory nerves, both $\mathrm{CN}$ IX and X contain branchial and visceral (parasympathetic) motor components, with cell bodies in the ventral neural tube that project axons forming a bundle between the hindbrain and the proximal and distal ganglia. A change in migration of NCCs as assessed by Crabp1 expression at the level of $\mathrm{r} 6 / 7$ was not detected in the Nav2 mutants, leaving abnormalities in the dorsal ventral migration of placode-derived neuronal precursors, improper guidance of motor neurons from CN IX to $\mathrm{CN} \mathrm{X}$, and abnormalities in axonal guidance molecules as other possible factors that could contribute to the CN IX/X defects observed in $\mathrm{Nav2}^{-/-}$embryos. In the present study, we have shown that the long Nav2 transcript (which encodes for the full-length protein) is expressed on or before E10.5 in the ganglia of CN IX and $\mathrm{X}$, a time when NCC emigration from the neural tube and placode-derived cell migration is largely complete and when axon elongation is actively underway. The appearance of Nav2 in the forming ganglia of $\mathrm{CN}$ IX and X together with earlier work supporting the importance of Nav2 in neurite outgrowth supports the proposal that defects in cranial nerve development result, at least in part, from defects in axonal elongation/directionality, although a defect in precursor cell migration cannot be ruled out at this time.

The development of CN IX and X is also perturbed when retinoid signaling is disrupted [10,52]. Fusion of CN IX and X has been reported in Raldh2 null mutant mice given a restricted period of supplemental atRA from E7.5 to E9.5 [10], as well as in Rar $\alpha / \beta$ [52] compound null mutant mice. atRA plays an important role in hindbrain patterning at early stages of development, and the RAR $\alpha / \beta$ compound null mutant mice show profound alterations in post-otic rhombomere identities that most likely explain the $\mathrm{CN}$ changes. In contrast, atRA-rescued Raldh2 null mutant mice show no apparent defect in hindbrain patterning, indicating that the $\mathrm{CN}$ abnormalities must have resulted from the effect of retinoid deficiency on later developmental events [10]. atRA plays a role in the stimulation of neurite outgrowth [6] and defects in this process are seen in retinoid-deficient embryos. It is known that expression of Nav2 mRNA is regulated by atRA, both in cultured cells and in developing embryos [27]. Because Nav2 is required for atRA-induced neurite outgrowth [31] and is found in CN IX and X in early embryos, it seems plausible that Nav2 may lie downstream of atRA and its receptors in the regulation of normal $\mathrm{CN}$ development.

$\mathrm{CN}$ IX and $\mathrm{X}$ are integral components of the homeostatic mechanism called the baroreceptor reflex that is important in maintaining blood pressure. The carotid sinus baroreceptors are innervated by the distal (petrosal) component of the glossopharyngeal nerve (CN IX) and the aorta by the distal (nodose) component of the vagus nerve $(\mathrm{CN} \mathrm{X})$. The visceromotor or parasympathetic component of the vagus nerve $(\mathrm{CN} \mathrm{X})$ also plays a role in the baroreceptor reflex to slow heart rate. In a normal animal, there is a linear relationship between the stretch of the baroreceptor containing vessel wall and the afferent nerve discharges [53]. With a rise in blood pressure, the carotid and aortic sinuses become distended, the baroreceptors fire action potentials, and this activity travels back to the nucleus of the solitary tract in the brainstrem via the afferent (sensory) components of the glossopharyngeal and vagus nerves. This causes inhibition of the sympathetic branch of the autonomic nervous system, and excites the nucleus ambiguous (vagal nuclei) that regulate the parasympathetic nervous system, leading to the release of acetylcholine at the sinoatrial node, slowing heart rate and conduction. Conversely, a decrease in blood pressure decreases baroreceptor firing, leading to an increase in sympathetic outflow and decreased parasympathetic (vagal) outflow. The present work shows that the ability of Nav2 mutants to respond to either an increase or decrease in blood pressure is blunted. Mice treated with a vasoconstrictor (angiotensin II) do not show the same reduction in heart rate as their wild-type counterparts, suggesting that the afferents of CN IX and X that relay this information to the brainstem, and/or the vagal ouput needed to slow the heart is defective. When a vasodialator (nitroprusside) was given, the Nav2 mutants showed less ability to increase heart rate, again, consistent with a defect in the afferent component of CN IX and/or X. The defects observed early in Nav2 hypomorphic mutant embryos support the conclusion that the functioning of CN IX and $\mathrm{X}$ is altered in adult mice. 
However, because the baroreceptor reflex is a complex process involving multiple components, other factors, including the responsiveness of the vessels, could also be involved.

\section{Conclusions}

We have provided in vivo evidence that the atRAresponsive gene Nav2 plays an important role in shaping the development of the mammalian nervous system. Elimination of the full-length Nav2 transcript and protein produces abnormalities in nerve fiber density as well as in the development of CN IX and X in early embryos. These $\mathrm{CN}$ defects may contribute to the reduced ability of adult Nav2 hypomorphic mutant mice to respond to acute changes in blood pressure due to abnormalities in the baroreceptor reflex.

\section{Methods}

\section{Embryo generation}

Embryos were generated from $\left(\mathrm{Nav} 2^{+/-} \times \mathrm{Nav} 2^{+/-}\right)$and female $\mathrm{Nav} 2^{+/-} \times$male $\mathrm{Nav} 2^{-/-}$crosses using C57BL/6Tyrc-Brd un53H2 mice as described [32] and were further backcrossed into $\mathrm{C} 57 / \mathrm{BL} / 6$ for up to six generations. Brn $3 a$ reporter mice were generated by crossing a Brn3a-lac $Z^{+/-}$mouse [38] with a Nav2 $2^{-/-}$mouse to generate $N a v 2^{+/-} / B r n 3 a-l a c z^{+/-}$mice; these were then bred to generate embryos for analysis that were Brn3a-lacz ${ }^{+/-}$ and $\mathrm{Nav}_{2}{ }^{+/+}, \mathrm{Nav}^{+/-}$and $\mathrm{Nav} 2^{-/-}$. Noon the day of vaginal plug detection was considered E0.5. At early developmental times, embryonic stage was further defined based on somitic development as follows: 1 to 3 somites (E8.0), 4 to 6 somites (E8.25), 7 to 10 somites (E8.5) and 11 to 14 somites (E9.0). Embryos were obtained by cesarean section and genotypes determined by taking a sample of yolk sac (<E9.0), tail or limb (E9.5 and up). Samples were processed using the Direct PCR Lysis Reagent for mouse yolk sac or tail (Viagen Biotech, Los Angeles, CA, USA) per the manufacturer's directions. Nav2 genotyping was performed as described previously [32] and Brn3a genotyping was done as described in [39]. The Brn3a reporter mouse was a kind gift from Dr Eric Turner (La Jolla, CA, USA).

\section{X-gal staining of embryos}

E12.5 and E13.5 embryos were fixed at room temperature in $4 \%$ paraformaldehyde (PFA) in phosphate-buffered saline (PBS) for 30 minutes and E15.5 embryos were fixed for 45 minutes. Embryos were then washed twice in PBS (pH 7.2 for all steps), and rinse buffer (5 mM EGTA, $2 \mathrm{mM} \mathrm{MgCl}_{2}, 0.01 \%$ sodium deoxycholate, and $0.02 \% \mathrm{NP}-40$ in PBS), each for 15 minutes at room temperature; embryos were then placed in staining solution $\left(5 \mathrm{mM} \mathrm{K}_{3} \mathrm{Fe}(\mathrm{CN})_{6}, 5 \mathrm{mM} \mathrm{K}_{4} \mathrm{Fe}(\mathrm{CN})_{6}, 5 \mathrm{mM}\right.$ EGTA, $2 \mathrm{mM} \mathrm{MgCl}_{2}, 0.01 \%$ sodium deoxycholate,
$0.5 \mathrm{mg} / \mathrm{ml} \mathrm{X}$-gal, $0.02 \% \mathrm{NP}-40$ in PBS). The embryos and tissues were incubated in the dark at $37^{\circ} \mathrm{C}$ for approximately $4 \mathrm{~h}$ or until the desired level of staining was reached. Embryos and tissues were washed in PBS for 10 minutes at room temperature, post-fixed in $4 \%$ PFA overnight at $4^{\circ} \mathrm{C}$, washed again in PBS at room temperature for 10 minutes and stored in PBS at $4^{\circ} \mathrm{C}$ until they were photographed using a Nikon model SMZ-U dissection microscope fitted with a $1 \times$ lens Qimaging camera and MetaMorph software (Molecular Devices, Downington, PA, USA).

\section{Whole-mount and vibratome in situ hybridization}

A partial Nav2 rat probe was used for in situ hybridization studies as described in [27]; the riboprobe was 93\% identical in nucleotide sequence to the mouse transcript (1,507-1,983 bp; NCBI accession number NM_001111016). The HoxA3 and Hoxb3 probes were a kind gift from Dr N Manley (Department of Genetics, University of Georgia, Athens, GA, USA), the Hoxb4. probe was generously provided by Dr R Krumlauf (Stowers Institute, Kansas City, MO, USA) and the Crabp1 probe was generated as described [54]. Whole-mount in situ hybridization was carried out using embryos fixed in $4 \%$ PFA by the methods previously described $[55,56]$ with the following modifications. The proteinase $\mathrm{K}(\mathrm{pK}) /$ refix times used at each stage were as follows: E8.5 (15/10 minutes), E9.5 (15/10 minutes; 10/8 minutes for Crabp1), E10.5 (20/15 minutes) for embryos in whole mount, and at 10.5 (8/10 minutes) for vibratome sections $(200 \mu \mathrm{m})$. Both antisense and sense probes were tested; no specific staining with sense probes was observed (data not shown). In situ hybridization of floating vibratome sections $(200 \mu \mathrm{m})$ was performed as described above except all incubations were performed in 24-well tissue culture plates. Sections were developed for 4 to $7 \mathrm{~h}$ on a rocker at room temperature. Embryos were processed and sectioned using a vibratome as previously described [57].

\section{Whole-mount immunohistochemistry}

Whole-mount immunohistochemistry for $2 \mathrm{H} 3$ was performed as described [58,59] and for Krox20 (EGR2) using previously described methods $[58,60]$. Briefly, embryos (E10.5 for 2H3; 8s for EGR2) were fixed overnight in 4\% PFA or Dent's fixative for $2 \mathrm{H} 3$ staining or in $4 \%$ PFA for EGR2. Embryos pretreated with $\mathrm{H}_{2} \mathrm{O}_{2}$ to quench endogenous peroxidase activity were incubated with either delipidated ascites, which were generated using a hybridoma (2H3) that secretes antibodies to neurofilament (Developmental Studies Hybridoma Bank, University of Iowa, Department of Biological Sciences, Iowa City, IA, USA) diluted 1:500 and 1:1,000 (for 4\% PFA or Dent's fixed tissues, respectively) in TBST 
(10 mM Tris, $\mathrm{pH} 8.0,150 \mathrm{mM} \mathrm{NaCl}, 0.05 \%$ Tween 20) or Krox20 antibody (Covance, Princeton, NJ, USA) diluted 1:1,000. This was followed by incubation with anti-mouse or anti-rabbit IgG conjugated to horseradish peroxidase (Southern Biotechnology Associates, Birmingham, AL, USA) diluted 1:1,000 in TBST. Embryos were pre-incubated in a solution of PBT con-

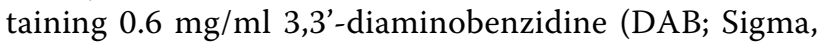
St Louis, MO, USA) with $0.75 \% \mathrm{NiCl}_{2}$ in PBT (PBS containing $0.05 \%$ Tween 20 ) followed by the addition of $\mathrm{H}_{2} \mathrm{O}_{2}$ to a final concentration of $0.03 \%$ for color development. 2H3-stained embryos in BABB (benzyl alcohol: benzyl benzoate) were first scored whole (to ensure that basic information was collected in the event that subsequent handling destroyed the sample) and were then sliced along the sagittal midplane, rescored and photographed as described above. EGR2-stained embryos were photographed in PBS.

\section{Baroreceptor testing}

Eighteen mice at 7 to 10 months of age, 9 male $\mathrm{Nav}^{+/+}$ and 9 male $\mathrm{Nav2}^{-/-}$animals, from $\mathrm{Nav2}^{+/-} \times \mathrm{Nav2}^{+/-}$ crosses (backcrossed to C57BL/6 for four generations) were tested for baroreceptor function at the UCLA Mouse Physiology Laboratory.

For the baroreceptor reflex study, mice were anesthetized and then both femoral arteries were catheterized to obtain a continuous recording of pressure and to provide a port to infuse drugs using methods adapted from [61]. The electrical signals from the pressure transducer and EKG electrodes were connected to bridge amplifiers (AstroMed Grass Technologies, Warwick, RI, USA). The pressure and EKG signals were digitized and displayed with HEM V4.0 software (Notocord Systems, Croissysur-Seine, France). All pressures were calibrated with a $\mathrm{Hg}$ manometer (Baumaster, FL, USA). Heart rates were calculated during the data acquisition by the HEM program from the R-R intervals of the EKG and from the arterial pressure waves.

The baroreceptor responsivity was assessed by a sequence of small bolus infusions $(0.08$ to $0.12 \mathrm{ml})$ of angiotensin II and sodium nitroprusside. First angiotensin II was given in three increasing doses of 0.5, 1.0 and 4 $\mu \mathrm{g} / \mathrm{kg}$. Infusions were separated by at least 5 minutes to permit drug wash out and re-stabilization to control pressure and heart rate levels. This was followed by the administration of three doses of sodium nitroprusside administered at 10, 20, and $40 \mu \mathrm{g} / \mathrm{kg}$. After at least 5 minutes of restabilization, propranolol was administered at $1 \mathrm{mg} / \mathrm{kg}$. This was immediately followed by an infusion of glycopyrrolate at $100 \mu \mathrm{g} / \mathrm{kg}$. After these autonomic blockers were administered and the animal stabilized, the high doses of angiotensin and sodium nitroprusside were repeated as controls. At the completion of the sequential infusions, the mouse was euthanized.

\section{Animals}

All animals were maintained according to conditions under a research protocol approved by the Institutional Animal Care and Use Committee at the University of Wisconsin-Madison. The baroreceptor studies were performed according to conditions under a research protocol approved by the UCLA Chancellor's Animal Research Committee.

\section{Statistics}

Statistical significance was determined by Chi-square analysis, Student's $t$ test, Z score testing or two-way analysis of variance (ANOVA). Student's $t$ test was done with Microsoft Excel, while $P$-values were generated from $\mathrm{Z}$ scores using P-Value Calculator [62]. Data are represented as averages of the mean \pm standard error, unless noted otherwise.

\section{Abbreviations}

atRA: all-trans retinoic acid; CN: cranial nerve; E: embryonic day; Nav2: neuron navigator 2; NB: neuroblastoma; NCC: neural crest cell; P: postnatal day; PFA: paraformaldehyde; PBS: phosphate-buffered saline; r: rhombomere.

\section{Acknowledgements}

We thank Elizabeth Roesler for assistance with animal colony maintenance, genotyping, and in situ hybridization and Tom Jeanne for help with in situ hybridization. Maria C Jordan assisted KPR with the baroreceptor studies at UCLA. We also thank E Turner for providing us with the Brn3a reporter strain. Additionally, we would like to thank Laura Vanderploeg and Adam Steinberg, Biochemistry Media Lab for figure artwork. EM McNeill was supported in part by a fellowship from NIH T32 DK07665.

\section{Author details}

${ }^{1}$ Interdepartmental Graduate Program in Nutritional Sciences, University of Wisconsin, Madison, WI, USA. ²Department of Physiology and the

Cardiovascular Research Lab, David Geffen School of Medicine at UCLA, Los Angeles, CA, USA. ${ }^{3}$ Johnson \& Johnson Pharmaceutical Research and Development, Beerse, Belgium. ${ }^{4}$ Department of Biochemistry, University of Wisconsin, Madison, WI, USA. ${ }^{5}$ Pharmaceutical Science Division, University of Wisconsin, Madison, WI, USA

\section{Authors' contributions}

EMM participated in study design, carried out studies of embryos, interpreted experiments and wrote the manuscript. KPR conducted baroreceptor response testing and interpretation. DM provided the Nav2 hypomorphic mouse strain. MCD participated in study design, interpretation and critical evaluation and revision of the manuscript.

\section{Competing interests}

The authors declare that they have no competing interests.

Received: 16 November 2009 Accepted: 25 February 2010 Published: 25 February 2010

\section{References}

1. Gavalas A, Krumlauf R: Retinoid signalling and hindbrain patterning. Curr Opin Genet Dev 2000, 10:380-386.

2. Clagett-Dame M, DeLuca HF: The role of vitamin A in mammalian reproduction and embryonic development. Annu Rev Nutr 2002, 22:347-381. 
3. Wilson L, Maden M: The mechanisms of dorsoventral patterning in the vertebrate neural tube. Dev Biol 2005, 282:1-13.

4. Glover JC, Renaud JS, Rijli FM: Retinoic acid and hindbrain patterning. IJ Neurobiol 2006, 66:705-725.

5. White RJ, Schilling TF: How degrading: Cyp26s in hindbrain development. Dev Dyn 2008, 237:2775-2790.

6. Clagett-Dame M, McNeill EM, Muley PD: Role of all-trans retinoic acid in neurite outgrowth and axonal elongation. J Neurobiol 2006, 66:739-756.

7. Mey J: New therapeutic target for CNS injury? The role of retinoic acid signaling after nerve lesions. J Neurobiol 2006, 66:757-779.

8. Maden M, Gale E, Kostetskii I, Zile M: Vitamin A-deficient quail embryos have half a hindbrain and other neural defects. Curr Biol 1996, 6:417-426.

9. White JC, Highland M, Kaiser M, Clagett-Dame M: Vitamin A deficiency results in the dose-dependent acquisition of anterior character and shortening of the caudal hindbrain of the rat embryo. Dev Biol 2000, 220:263-284.

10. Niederreither K, Vermot J, Le Roux I, Schuhbaur B, Chambon P, Dollé P: The regional pattern of retinoic acid synthesis by RALDH2 is essential for the development of posterior pharyngeal arches and the enteric nervous system. Development 2003, 130:2525-2534.

11. Haskell BE, Stach RW, Werrbach-Perez K, Perez-Polo JR: Effect of retinoic acid on nerve growth factor receptors. Cell Tissue Res 1987, 247:67-73.

12. Quinn SD, De Boni U: Enhanced neuronal regeneration by retinoic acid of murine dorsal root ganglia and of fetal murine and human spinal cord in vitro. In Vitro Cell Dev Biol 1991, 27:55-62.

13. Rodriguez-Tebar A, Rohrer H: Retinoic acid induces NGF-dependent survival response and high-affinity NGF receptors in immature chick sympathetic neurons. Development 1991, 112:813-820.

14. Plum LA, Clagett-Dame M: All-trans retinoic acid stimulates and maintains neurite outgrowth in nerve growth factor-supported developing chick embryonic sympathetic neurons. Dev Dyn 1996, 205:52-63.

15. Plum LA, Parada LF, Tsoulfas P, Clagett-Dame M: Retinoic acid combined with neurotrophin-3 enhances the survival and neurite outgrowth of embryonic sympathetic neurons. Exp Biol Med 2001, 226:766-775.

16. Wuarin $L$, Sidell $N$, de Vellis J: Retinoids increase perinatal spinal cord neuronal survival and astroglial differentiation. Int J Dev Neurosci 1990, 8:317-326

17. Sidell N, Altman A, Haussler MR, Seeger RC: Effects of retinoic acid (RA) on the growth and phenotypic expression of several human neuroblastoma cell lines. Exp Cell Res 1983, 148:21-30.

18. Abemayor $\mathrm{E}$, Sidell N: Human neuroblastoma cell lines as models for the in vitro study of neoplastic and neuronal cell differentiation. Environ Health Perspect 1989, 80:3-15.

19. Horton C, Maden M: Endogenous distribution of retinoids during normal development and teratogenesis in the mouse embryo. Dev Dyn 1995, 202:312-323.

20. Hoover F, Gundersen TE, Ulven SM, Michaille JJ, Blanchet S, Blomhoff R, Glover JC: Quantitative assessment of retinoid signaling pathways in the developing eye and retina of the chicken embryo. J Comp Neurol 2001, 436:324-335.

21. Werner EA, Deluca HF: Retinoic acid is detected at relatively high levels in the CNS of adult rats. Am J Physiol Endocrinol Metab 2002, 282:E672-678.

22. McCaffery $P$, Lee MO, Wagner MA, Sladek NE, Dräger UC: Asymmetrical retinoic acid synthesis in the dorsoventral axis of the retina. Development 1992, 115:371-382.

23. Wagner $E$, Luo T, Drager UC: Retinoic acid synthesis in the postnatal mouse brain marks distinct developmental stages and functional systems. Cereb Cortex 2002, 12:1244-1253.

24. Duester G: Retinoic acid synthesis and signaling during early organogenesis. Cell 2008, 134:921-931.

25. Blomhoff R, Blomhoff HK: Overview of retinoid metabolism and function. J Neurobiol 2006, 66:606-630.

26. Chambon P: A decade of molecular biology of retinoic acid receptors FASEB J 1996, 10:940-954.

27. Merrill RA, Plum LA, Kaiser ME, Clagett-Dame M: A mammalian homolog of unc- 53 is regulated by all-trans retinoic acid in neuroblastoma cells and embryos. Proc Natl Acad Sci USA 2002, 99:3422-3427.

28. Maes T, Barcelo A, Buesa C: Neuron navigator: a human gene family with homology to unc-53, a cell guidance gene from Caenorhabditis elegans. Genomics 2002, 80:21-30
29. Coy JF, Wiemann S, Bechmann I, Bächner D, Nitsch R, Kretz O, Christiansen $\mathrm{H}$, Poustka A: Pore membrane and/or filament interacting like protein 1 (POMFIL1) is predominantly expressed in the nervous system and encodes different protein isoforms. Gene 2002, 290:73-94.

30. Ishiguro H, Shimokawa T, Tsunoda T, Tanaka T, Fujii Y, Nakamura Y, Furukawa Y: Isolation of HELAD1, a novel human helicase gene upregulated in colorectal carcinomas. Oncogene 2002, 21:6387-6394.

31. Muley PD, McNeill EM, Marzinke MA, Knobel KM, Barr MM, Clagett-Dame M: The atRA-responsive gene neuron navigator 2 functions in neurite outgrowth and axonal elongation. Dev Neurobiol 2008, 68:1441-1453.

32. Peeters PJ, Baker A, Goris I, Daneels G, Verhasselt P, Luyten WH, Geysen JJ, Kass SU, Moechars DW: Sensory deficits in mice hypomorphic for a mammalian homologue of unc-53. Brain Res Dev Brain Res 2004, 150:89-101.

33. Stringham E, Pujol N, Vandekerckhove J, Bogaert T: unc-53 controls longitudinal migration in C. elegans. Development 2002, 129:3367-3379.

34. Hedgecock EM, Culotti JG, Hall DH, Stern BD: Genetics of cell and axon migrations in Caenorhabditis elegans. Development 1987, 100:365-382.

35. Chen EB, Branda CS, Stern MJ: Genetic enhancers of sem-5 define components of the gonad-independent guidance mechanism controlling sex myoblast migration in Caenorhabditis elegans hermaphrodites. Dev Biol 1997, 182:88-100.

36. Siddiqui SS: Mutations affecting axonal growth and guidance of motor neurons and mechanosensory neurons in the nematode Caenorhabditis elegans. Neurosci Res Suppl 1990, 13:S171-190.

37. Hekimi S, Kershaw D: Axonal guidance defects in a Caenorhabditis elegans mutant reveal cell-extrinsic determinants of neuronal morphology. J Neurosci 1993, 13:4254-4271.

38. Quina LA, Pak W, Lanier J, Banwait P, Gratwick K, Liu Y, Velasquez T, O'Leary DD, Goulding M, Turner EE: Brn3a-expressing retinal ganglion cells project specifically to thalamocortical and collicular visual pathways. J Neurosci 2005, 25:11595-11604.

39. Eng SR, Gratwick K, Rhee JM, Fedtsova N, Gan L, Turner EE: Defects in sensory axon growth precede neuronal death in Brn3a-deficient mice. J Neurosci 2001, 21:541-549.

40. Cordes SP: Molecular genetics of cranial nerve development in mouse. Nat Rev Neurosci 2001, 2:611-623.

41. Schneider-Maunoury S, Topilko P, Seitandou T, Levi G, Cohen-Tannoudji M, Pournin S, Babinet C, Charnay P: Disruption of Krox-20 results in alteration of rhombomeres 3 and 5 in the developing hindbrain. Cell 1993, 75:1199-1214

42. Manley NR, Capecchi MR: Hox group 3 paralogous genes act synergistically in the formation of somitic and neural crest-derived structures. Dev Biol 1997, 192:274-288.

43. Watari N, Kameda Y, Takeichi M, Chisaka O: Hoxa3 regulates integration of glossopharyngeal nerve precursor cells. Dev Biol 2001, 240:15-31.

44. Shepherd AM, Lin MS, McNay JL, Musgrave GE, Keeton TK: Baroreflex sensitivity modulates vasodepressor response to nitroprusside. Hypertension 1983, 5:79-85.

45. Martinez-Lopez MJ, Alcántara S, Mascaró C, Pérez-Brangulí F, Ruiz-Lozano P, Maes T, Soriano E, Buesa C: Mouse neuron navigator 1, a novel microtubule-associated protein involved in neuronal migration. Mol Cell Neurosci 2005, 28:599-612.

46. van Haren J, Draegestein K, Keijzer N, Abrahams JP, Grosveld F, Peeters PJ Moechars D, Galjart N: Mammalian navigators are microtubule plus-end tracking proteins that can reorganize the cytoskeleton to induce neurite-like extensions. Cell Motil Cytoskeleton 2009, 66:824-838.

47. Schmidt KL, Marcus-Gueret N, Adeleye A, Webber J, Baillie D, Stringham EG: The cell migration molecule UNC-53/NAV2 is linked to the ARP2/3 complex by ABI-1. Development 2009, 136:563-574.

48. Gavalas A: ArRAnging the hindbrain. Trends Neurosci 2002, 25:61-64.

49. Qiu Y, Pereira FA, DeMayo FJ, Lydon JP, Tsai SY, Tsai MJ: Null mutation of mCOUP-TFI results in defects in morphogenesis of the glossopharyngeal ganglion, axonal projection, and arborization. Genes Dev 1997, 11:1925-1937.

50. Parrish M, Ott T, Lance-Jones C, Schuetz G, Schwaeger-Nickolenko A, Monaghan AP: Loss of the Sall3 gene leads to palate deficiency, abnormalities in cranial nerves, and perinatal lethality. Mol Cell Biol 2004, 24:7102-7112. 
51. Hatakeyama J, Sakamoto S, Kageyama R: Hes1 and Hes5 regulate the development of the cranial and spinal nerve systems. Dev Neurosci 2006, 28:92-101.

52. Dupe V, Ghyselinck NB, Wendling O, Chambon P, Mark M: Key roles of retinoic acid receptors alpha and beta in the patterning of the caudal hindbrain, pharyngeal arches and otocyst in the mouse. Development 1999, 126:5051-5059.

53. Andresen MC, Krauhs JM, Brown AM: Relationship of aortic wall and baroreceptor properties during development in normotensive and spontaneously hypertensive rats. Circ Res 1978, 43:728-738.

54. Stoner CM, Gudas LJ: Mouse cellular retinoic acid binding protein: cloning, clomplementary DNA sequence, and messenger RNA expression during the retinoic acid-induced differentiation of F9 wild type and RA-3-10 mutant teratocarcinoma cells. Cancer Res 1989, 49:1497-1504

55. Kaiser ME, Merrill RA, Stein AC, Breburda E, Clagett-Dame M: Vitamin A deficiency in the late gastrula stage rat embryo results in a one to two vertebral anteriorization that extends throughout the axial skeleton. Dev Biol 2003, 257:14-29.

56. Wilkinson DG: In Situ Hybridization: A Practical Approach. Hames BD (Series Editor): The Practical Approach Series New York: Oxford University Press, 2 1998.

57. See AW, Clagett-Dame M: The temporal requirement for vitamin A in the developing eye: mechanism of action in optic fissure closure and new roles for the vitamin in regulating cell proliferation and adhesion in the embryonic retina. Dev Biol 2009, 325:94-105.

58. Wall NA, Jones $C M$, Hogan BL, Wright CV: Expression and modification of Hox 2.1 protein in mouse embryos. Mech Dev 1992, 37:111-120.

59. White JC, Shankar VN, Highland M, Epstein ML, DeLuca HF, ClagettDame M: Defects in embryonic hindbrain development and fetal resorption resulting from vitamin A deficiency in the rat are prevented by feeding pharmacological levels of all-trans-retinoic acid. Proc Natl Acad Sci USA 1998, 95:13459-13464.

60. Goddard JM, Rossel M, Manley NR, Capecchi MR: Mice with targeted disruption of Hoxb-1 fail to form the motor nucleus of the Vllth nerve. Development 1996, 122:3217-3228.

61. Holschneider DP, Scremin OU, Roos KP, Chialvo DR, Chen K, Shih JC Increased baroreceptor response in mice deficient in monoamine oxidase A and B. Am J Physiol Heart Circ Physiol 2002, 282:H964-972.

62. P-Value Calculator. [http://www.graphpad.com/quickcalcs/pvalue1.cfm].

63. Raffa RB, Rawls S, Beyzarov E: Netter's Illustrated Pharmacology Teterboro, NJ: Icon Learning Systems 2004.

doi:10.1186/1749-8104-5-6

Cite this article as: McNeill et al: Nav2 is necessary for cranial nerve development and blood pressure regulation. Neural Development 2010 5:6.

\section{Submit your next manuscript to BioMed Central and take full advantage of:}

- Convenient online submission

- Thorough peer review

- No space constraints or color figure charges

- Immediate publication on acceptance

- Inclusion in PubMed, CAS, Scopus and Google Scholar

- Research which is freely available for redistribution 